Original Article

\title{
Changes in muscle strength and endurance of professional cyclists due to PycnoRacer ${ }^{\mathrm{TM}}$
}

Tatsuya Igawa, RPT, PhD ${ }^{1,2)^{*}}$, Tsuyoshi Hara, RPT, $\mathrm{PhD}^{1,2)}$, Masahiro Ishizaka, RPT, PhD ${ }^{1)}$, Yohei SAwaya, RPT, MS ${ }^{1,3)}$, Akihiro Ito, RPT, PhD ${ }^{1,2)}$, Akihiro Yakabi, RPT, PhD ${ }^{1,4)}$, Akira Kubo, RPT, $\mathrm{PhD}^{1,4)}$

1) Department of Physical Therapy, School of Health Science, International University of Health and Welfare: 2600-1 Kitakanemaru, Ohtawara, Tochigi 324-8501, Japan

2) Department of Rehabilitation, International University of Health and Welfare Hospital, Japan

3) Department of Day Rehabilitation, Nishinasuno General Home Care Center, Japan

4) Department of Rehabilitation, International University of Health and Welfare Shioya Hospital, Japan

\begin{abstract}
Purpose] Changes in the muscle performance of professional motorized athletes using pycnogenolcontaining supplements have not been clarified. The purpose of this study was to evaluate the changes in muscle strength and endurance of professional cyclists during 4 weeks of training with the use of PycnoRacer ${ }^{\mathrm{TM}}$. [Participants and Methods] Eight professional cyclists were requested to consume PycnoRacer ${ }^{\mathrm{TM}}$ twice/day for 4 weeks. The muscle endurance test consisted of 50 consecutive knee flexion and extension exercises at $180 \%$ sec using an isokinetic torque machine before and after PycnoRacer ${ }^{\mathrm{TM}}$ administration. The athletes' body composition, including leg muscle mass, was also measured. [Results] The maximum flexor muscle torque and 41 st-50th flexion muscle torque values significantly improved after supplement consumption (average improvement of $8.5 \%$; range, $13.3-$ 67.2\%). The leg muscle mass and body composition did not differ significantly between the two conditions. The participants showed an average improvement of 31.8\% (range, 0.9-67.8\%) in their total work with cycling training. No adverse events were observed. [Conclusion] The use of PycnoRacer ${ }^{\mathrm{TM}}$ may improve training, muscle strength, and endurance, but not muscle mass.

Key words: Cyclist, Pycnogenol, Muscle endurance
\end{abstract}

(This article was submitted Nov. 24, 2020, and was accepted Jan. 14, 2021)

\section{INTRODUCTION}

Athletes who perform rigorous endurance exercises such as marathons, triathlons, and cycling must train to cope with the varying levels of fatigue for improving their physical activity abilities. Overloading the body with increased training can cause muscle soreness and stiffness, increased oxidative stress, muscle cramps, and even immunosuppression ${ }^{1,2)}$. These problems can be prevented by establishing an appropriate training and reconditioning program. Dietary supplements containing certain nutrients also improve performance and recovery ${ }^{3-5}$. It has been reported that antioxidant supplements improve endurance cycling performance ${ }^{3)}$ and recovery of post-exercise muscle performance ${ }^{4)}$. Pycnogenol, a French coastal pine bark extract rich in antioxidants, is used for various clinical symptoms, such as cognitive impairment, menopausal symptoms, arthralgia, and menstrual pain, and its strong antioxidant effects have been previously reported ${ }^{6-9}$. Recent studies demonstrate that Pycnogenol was used by amateur athletes for reducing muscle pain and stiffness and improving running performance, such as the Cooper test and maximum oxygen consumption ${ }^{10-12)}$. While it is relatively easy for amateur athletes to improve their athletic performance through training, professional athletes have a high level of motor skill, and therefore their improvement

*Corresponding author. Tatsuya Igawa (E-mail: t.igawa@iuhw.ac.jp)

(C2021 The Society of Physical Therapy Science. Published by IPEC Inc.

(c) $(-)$ This is an open-access article distributed under the terms of the Creative Commons Attribution Non-Commercial No DerivaCC BY NC ND tives (by-nc-nd) License. (CC-BY-NC-ND 4.0: https://creativecommons.org/licenses/by-nc-nd/4.0/) 
is in smaller increments than that for amateur athletes ${ }^{13}$. There have been no previous reports on the improvement of muscle strength and endurance of highly motorized professional athletes using Pycnogenol. We believe that endurance professional athletes, after using Pycnogenol supplements, will achieve improvements in muscle pain, local muscle performance including muscle strength and endurance, and the amount of training.

The purposes of this study were to evaluate the amount of training, muscle strength, and endurance before and after the intake of Pycnogenol in professional cyclists with high endurance performance and to clarify the changes.

\section{PARTICIPANTS AND METHODS}

Eight professional healthy male cyclists (mean \pm standard deviation (SD); age, $24.0 \pm 2.4$ years; height, $172.1 \pm 5.4 \mathrm{~cm}$; body weight, $63.2 \pm 3.2 \mathrm{~kg}$; and $\mathrm{VO}_{2} \mathrm{max}, 71.4 \pm 6.5 \mathrm{~mL} / \mathrm{min} / \mathrm{kg}$ ) participated in this study. Participants belonged to a professional team registered as the UCI Continental Teams and performed high-intensity cycling training more than 4 days a week. Those who had taken supplements containing antioxidants during the past month, who underwent surgery for orthopedic or cardiovascular diseases within the past month, and who were scheduled at the start of the study to undergo surgery were excluded from this study. Of the 10 athletes belonging to this team, 8 athletes, except the 2 athletes who met the exclusion criteria, participated in this study. No cyclist was taking banned drugs or medications, and none of them tested positive in the routine doping tests performed according to the World Anti-Doping Agency.

Prior to initiating this study, the study protocol was reviewed and approved by the International University of Health and Welfare Institutional Review Ethics Committee (registration 19-Io-18-2), and written consent was obtained from the participants in agreement with the Declaration of Helsinki before participation.

Data were collected during a 10-week preseason training period (January to March). This is a case study of a prospective observational design measuring muscle endurance as the main outcome before and after a 4-week training period with antioxidative supplements. PycnoRacer ${ }^{\mathrm{TM}}$ is a fitness drink containing Pycnogenol $(15 \mathrm{mg})$, L-leucine $(0.6 \mathrm{~g})$, L-arginine $(0.3 \mathrm{~g}), \mathrm{L}$-isoleucine $(0.3 \mathrm{~g})$, and L-valine $(0.3 \mathrm{~g})$. All the athletes were instructed to use PycnoRacer ${ }^{\mathrm{TM}}$ twice/day for 4 weeks, as recommended by the manufacturer.

To assess the muscle endurance of the quadriceps femoris and hamstrings, a test was performed using an isokinetic dynamometer. The evaluation of muscle strength through an isokinetic dynamometer has been used in the diagnosis of neuromuscular disorders, rehabilitation, training, and research, and as an indicator of the function and performance of certain muscle groups ${ }^{14}$. System 4 Pro Biodex ${ }^{\circledR}$ isokinetic dynamometer (BioDex Medical Inc., NY, USA) was used for assessing muscle fatigue. The established isokinetic protocol was that of concentric contractions at $180^{\circ} \mathrm{s}$ with 50 repetitions, and with a brief rest period (up to 5-10 $\mathrm{min}$ ) between both the lower extremities. The equipment was calibrated to the range of motion from the maximum flexion to the maximum extension for each participant. Participants were asked to make three movements of extension and flexion at a submaximal intensity to complete the warm-up process and familiarize themselves with the equipment and testing procedures. Subsequently, the test was initiated, whereupon a verbal command was given by the same examiner during all the tests ${ }^{15}$. In addition to the peak torque of flexion and extension, we calculated the average torque of the 31 st to 40 th and 41 st to 50 th repetition for evaluation of the muscle endurance ${ }^{16,17)}$.

A visual analog scale (VAS) was utilized for assessing perceived muscular soreness as described in a previous study ${ }^{18)}$. The scale was a straight horizontal line, $100 \mathrm{~mm}$ in length, and the athletes were asked to "mark on the line below indicating how sore you are at this moment" immediately after the muscle endurance test. The evaluation form was stated with the verbal anchors "not impairing=0" and "highly impairing=100".

Athletes were also measured for body composition using direct segmental multifrequency bioelectrical impedance analysis method (BIA) (Inbody520, Biospace, Japan). For the measurement items, body weight, body mass index, leg muscle mass, and percentage body fat were obtained. All food and drink and moderate or higher exercise 360 minutes prior to measurement were restricted to account for the effects of increased and decreased impedance.

During the training period, the participants were evaluated for fitness and performance by using a pedaling monitor system (pioneer, SGY-PM910H, Japan; pioneer, SGX-CA600, Japan). Researchers calculated the total work conducted over the previous 4 weeks to assess the amount of training. Participants adhered to their own training plan identical between before and after the intake of PycnoRacer ${ }^{\mathrm{TM}}$.

Participants' dietary habits regarding food and drink, including caffeine and other dietary supplements, were recorded using a questionnaire. During the study period, the participants did not change their normal diet. Athletes were asked to check their diet for compliance when they arrived at the laboratory.

Statistical analyses were performed using SPSS version 25 (IBM, Armork, NY, USA). Descriptive results were expressed as mean $\pm \mathrm{SD}$. The Wilcoxon signed-rank test was used for assessing differences in the variables before and after 4-week training period with antioxidative supplement. The level of statistical significance was set at $\mathrm{p}<0.05$.

\section{RESULTS}

There were no missing data among the dependent variables of all the participants. There was a moderate increase in knee flexor isokinetic peak torques $(+13.3 \%$, $<<0.05$, effect size $(E S)=0.63)$ and 41 st -50 th muscle torques $(+9.9 \%$, $p<0.05$, 
$\mathrm{ES}=0.53$ ) after the training period (Table 1). Although the $31 \mathrm{st}-40$ th torques $(+13.5 \%, \mathrm{p}=0.08, \mathrm{ES}=0.44)$ after supplement consumption tended to increase compared to before, but no statistically significant difference was observed. There was no significant change in knee extensor peak torques $(+4.3 \%, \mathrm{p}=0.12, \mathrm{ES}=0.39), 31 \mathrm{st}-40$ th torques $(-2.1 \%, \mathrm{p}=0.47, \mathrm{ES}=0.18)$, and 41 st -50 th muscle torques $(-0.4 \%, \mathrm{p}=0.80, \mathrm{ES}=0.07)$ after the training period. There was no significant difference in muscle soreness before and after supplementation (Table 2). Although the amount of training during the past 4 weeks significantly increased after supplementation compared to that before supplementation $(+31.8 \%, \mathrm{p}<0.05$, ES $=0.89)$, there was no change in body composition, including leg muscle mass (Table 3). The participants experienced no adverse events during the 10 -week training period.

\section{DISCUSSION}

There have been no previous reports on the improvement of muscle strength and endurance of professional cyclists using Pycnogenol. This study evaluates the changes in muscle strength and endurance of professional cyclists in 4 weeks of training using PycnoRacer ${ }^{\mathrm{TM}}$. In our study, we observed that the use of PycnoRacer ${ }^{\mathrm{TM}}$ improved training, endurance, and muscle strength; however, the no effects on muscle mass were observed.

Recovery from fatigue after high-intensity training is important for improving the performance of athletes. There are many reports analyzing cyclist fatigue using blood data, including metabolites such as lactate concentration, C-reactive protein, and creatine kinase, in addition to maximum oxygen intake ${ }^{19-22)}$. However, no study has analyzed the muscular fatigue of

Table 1. Comparison of knee joint torque between before and after 4-week training period

\begin{tabular}{|c|c|c|c|c|c|}
\hline & \multicolumn{2}{|c|}{ Pre } & \multicolumn{2}{|c|}{ Post } & \multirow{2}{*}{$\mathrm{p}$ value } \\
\hline & Mean & SD & Mean & SD & \\
\hline \multicolumn{6}{|l|}{ Extension } \\
\hline Peak torque $(\mathrm{Nm} / \mathrm{kg})$ & 1.6 & 0.3 & 1.7 & 0.4 & 0.12 \\
\hline 31 st -40 th torque $(\mathrm{Nm} / \mathrm{kg})$ & 1.1 & 0.1 & 1.1 & 0.2 & 0.47 \\
\hline $41 \mathrm{st}-50$ th torque $(\mathrm{Nm} / \mathrm{kg})$ & 1.0 & 0.2 & 1.0 & 0.2 & 0.80 \\
\hline \multicolumn{6}{|l|}{ Flexion } \\
\hline Peak torque $(\mathrm{Nm} / \mathrm{kg})$ & 1.3 & 0.2 & 1.5 & 0.2 & $0.01^{*}$ \\
\hline $31 \mathrm{st}-40$ th torque $(\mathrm{Nm} / \mathrm{kg})$ & 1.0 & 0.3 & 1.0 & 0.2 & 0.08 \\
\hline 41st-50th torque $(\mathrm{Nm} / \mathrm{kg})$ & 0.9 & 0.2 & 1.0 & 0.2 & $0.03^{*}$ \\
\hline
\end{tabular}

Statistical analyses were conducted with the Wilcoxon signed-rank test.

*Statistically significant $\mathrm{p}<0.05 ; \mathrm{SD}$ : standard deviation.

Table 2. Comparison of muscle soreness immediately after muscle performance test between before and after 4-week training period

\begin{tabular}{lcccccc}
\hline & \multicolumn{3}{c}{ Pre } & & \multicolumn{3}{c}{ Post } & \multirow{2}{*}{ p value } \\
\cline { 2 - 3 } \cline { 5 - 7 } & Mean & SD & & Mean & SD & \\
\hline Quadriceps femoris & 83.8 & 8.1 & & 86.3 & 12.0 & 0.21 \\
Hamstrings & 61.9 & 21.0 & & 65.0 & 23.4 & 0.30 \\
\hline
\end{tabular}

Statistical analyses were conducted with the Wilcoxon signed-rank test.

SD: standard deviation.

Table 3. Comparison of body composition and the amount of cycling training between before and after 4-week training period

\begin{tabular}{lccccccc}
\hline & \multicolumn{2}{c}{ Pre } & & \multicolumn{2}{c}{ Post } & \multirow{2}{*}{$\mathrm{p}$ value } \\
\cline { 2 - 3 } \cline { 5 - 6 } & Mean & SD & & Mean & SD & & 0.08 \\
Body weight $(\mathrm{kg})$ & 63.2 & 3.2 & & 62.3 & 3.0 & 0.11 \\
Body mass index $\left(\mathrm{kg} / \mathrm{m}^{2}\right)$ & 21.4 & 1.5 & & 21.0 & 1.4 & 0.28 \\
Leg muscle mass $(\mathrm{kg})$ & 8.5 & 0.6 & & 8.5 & 0.6 & 0.11 \\
Percent body fat $(\%)$ & 14.5 & 2.3 & & 13.9 & 2.5 & & $0.02^{*}$ \\
Total work of cycling training $(\mathrm{kJ})$ & $27,632.3$ & $10,711.4$ & & $34,694.6$ & $10,558.7$ & \\
\hline
\end{tabular}

Statistical analyses were conducted with the Wilcoxon signed-rank test.

*Statistically significant $\mathrm{p}<0.05$; SD: standard deviation. 
cyclists from the viewpoint of local muscle performance. This is the first report on professional cyclists who have continuously taken supplements containing Pycnogenol and achieved increased muscle performance, including muscle strength and endurance, and the amount of training. Clinical studies using various types of antioxidants have reported beneficial effects, such as improvement in cardiovascular response during exercise, recovery of muscle performance, optimization of skeletal muscle oxygenation concentration, force generation and power increase during high-intensity endurance exercise, recovery after muscle damage by anti-inflammatory mechanisms, and reduction of muscle fatigue ${ }^{23-26)}$. Therefore, it is speculated that these mechanisms might be involved in the professional cyclists who regularly use Pycnogenol, and the amount of training increased after the supplement intake compared to before the supplement intake. Athletes who compete in triathlon, which is the same endurance sport activity as cycling, have been reported to have significantly reduced local muscle function, including knee muscle strength after the race ${ }^{27,28)}$. One of the most effective methods for evaluating the degree of muscle damage is to measure muscle function, such as strength and power ${ }^{29}$. Improving local muscle function around the knee is one of the most important training tasks for cyclists. Muscle endurance, which means the aerobic capacity, depends on the oxygen supply to the muscle. The supplement used in this study contains Pycnogenol, which has a peripheral vasodilatory effect, and l-arginine, which has a vasodilatory and blood flow promoting effect. After 4 weeks of PycnoRacer ${ }^{\mathrm{TM}}$ intake, muscle blood flow, and oxygen intake may have increased, possibly increasing the oxygen supply to the flexor muscles of the knee joint. Furthermore, PycnoRacer ${ }^{\mathrm{TM}}$ contains the essential amino acids branched-chain amino acids (BCAAs). BCAAs affect recovery from fatigue by controlling the increase in serotonin and 5-hydroxyindoleacetic acid levels after exercise $^{30)}$. In clinical trials in athletes, BCAAs have been reported to affect psychomotor performance, such as increased reaction time during exercise ${ }^{31)}$. The relationship between arginine intake, improved performance, and growth hormone secretion in athletes remains unclear ${ }^{32,33)}$. Future studies will need to investigate the relationship between professional cyclist serotonin and 5-hydroxyindoleacetic acid levels, the growth hormone section, and PycnoRacer ${ }^{\mathrm{TM}}$, which contains BCAAs and arginine. Hamstring muscles have a higher proportion of type II fibers compared to quadriceps, and both have structural and metabolic differences ${ }^{34-36)}$. Hamstrings are more prone to fatigue than quadriceps because fast type II fibers are more prone to fatigue than slow type I fibers. To reduce local muscle fatigue during cycling competitions, various muscle groups of the lower limbs coordinate to activate and interpolate energy consumption, and voluntarily adjust the posture ${ }^{37,38)}$. Therefore, although the improvement in muscle endurance may be due to the improvement in peak torque, the result of this study that the endurance of hamstring muscles is improved is useful in cycling competition. In addition to physiological mechanisms, changes in these muscle performances may simply result from increased training at 4 weeks after supplement intake. This is because increasing the amount of training also improves muscle strength and endurance according to the training principles of overload. While muscle strength and endurance were increased, there was no change in lower limb muscle mass and muscle pain immediately after the measurement. It is conceivable that muscle hypertrophy of the lower limbs did not occur and that the athletes were able to exert high muscle performance with the same level of muscle soreness as before taking the supplement. Considering the physiological theory that muscle pain and/or muscle fatigue increase as the exerted muscle strength increases, it is speculated that this supplement has a local muscle soreness relieving effect. It is speculated that muscle pain was not enhanced because of the anti-inflammatory and fatigue-reducing effects of antioxidants ${ }^{8,39)}$. Unfortunately, it is not possible to clarify the in vivo inflammatory and fatigue response obtained from the collected blood. In the future, it is necessary to conduct different analysis for investigating the relationship between the supplements containing Pycnogenol and metabolic circulatory responses.

This study has some limitations. First, since the participants of this study are athletes who belong to a particular team, there is a selection bias. Therefore, it is not a result that can be generalized to professional cyclists. Second, there were no placebo controls for the participants of this study. Since the supplement may have been prescribed to interested participants, the results may have been biased. It is unclear whether the effects of supplements or increased training levels affected the results. It is necessary to conduct a cross-over design study while taking measures, such as blinding to exposure, recruiting participants from multiple teams, and increasing the number of participants. Third, in this study, the amount of training was assessed using only total work values. It cannot be judged from the value of total work whether the exercise was performed for an extended period time under a low load or for a short period under a high load. There are other indicators that reflect the amount of training, such as a training stress score calculated from the power consumption level of force and normalized power that represents exercise intensity. In the future, it is necessary to investigate the amount of training in detail including the above values.

In conclusion, eight male professional cyclists who used PycnoRacer ${ }^{\mathrm{TM}}$ during the training period showed improvement of muscle strength and endurance without side effects. However, the efficacy of training with PycnoRacer ${ }^{\mathrm{TM}}$ alone by professional cyclists is unknown because no control group setting. Further investigation is required by a crossover study with a placebo.

\section{Funding}

This study was funded by KOBAYASHI Pharmaceutical Co., Ltd.

\section{Conflict of interest}

The authors declare no conflict of interest. The source of funding was not involved in research implementation, research design, and analysis. 


\section{ACKNOWLEDGEMENT}

The authors are grateful to Mr. Kota Iwai, general manager of NASU BLASEN, for suggesting the topic and for collaboration on the early stages of this work.

\section{REFERENCES}

1) Suzuki K, Nakaji S, Yamada M, et al.: Impact of a competitive marathon race on systemic cytokine and neutrophil responses. Med Sci Sports Exerc, 2003, 35: 348-355. [Medline] [CrossRef]

2) Suzuki K, Totsuka M, Nakaji S, et al.: Endurance exercise causes interaction among stress hormones, cytokines, neutrophil dynamics, and muscle damage. J Appl Physiol 1985, 1999, 87: 1360-1367. [Medline]

3) Crum EM, Che Muhamed AM, Barnes M, et al.: The effect of acute pomegranate extract supplementation on oxygen uptake in highly-trained cyclists during high-intensity exercise in a high altitude environment. J Int Soc Sports Nutr, 2017, 14: 14. [Medline] [CrossRef]

4) Torregrosa-García A, Ávila-Gandía V, Luque-Rubia AJ, et al.: Pomegranate extract improves maximal performance of trained cyclists after an exhausting endurance trial: a randomised controlled trial. Nutrients, 2019, 11: 721. [Medline] [CrossRef]

5) Castell LM, Newsholme EA: The effects of oral glutamine supplementation on athletes after prolonged, exhaustive exercise. Nutrition, 1997, 13: 738-742. [Medline] [CrossRef]

6) Ryan J, Croft K, Mori T, et al.: An examination of the effects of the antioxidant Pycnogenol on cognitive performance, serum lipid profile, endocrinological and oxidative stress biomarkers in an elderly population. J Psychopharmacol, 2008, 22: 553-562. [Medline] [CrossRef]

7) Yang HM, Liao MF, Zhu SY, et al.: A randomised, double-blind, placebo-controlled trial on the effect of Pycnogenol on the climacteric syndrome in perimenopausal women. Acta Obstet Gynecol Scand, 2007, 86: 978-985. [Medline] [CrossRef]

8) Belcaro G, Cesarone MR, Errichi S, et al.: Treatment of osteoarthritis with Pycnogenol. The SVOS (San Valentino Osteo-arthrosis Study). Evaluation of signs, symptoms, physical performance and vascular aspects. Phytother Res, 2008, 22: 518-523. [Medline] [CrossRef]

9) Suzuki N, Uebaba K, Kohama T, et al.: French maritime pine bark extract significantly lowers the requirement for analgesic medication in dysmenorrhea: a multicenter, randomized, double-blind, placebo-controlled study. J Reprod Med, 2008, 53: 338-346. [Medline]

10) Vinciguerra G, Belcaro G, Cesarone MR, et al.: Cramps and muscular pain: prevention with pycnogenol in normal subjects, venous patients, athletes, claudicants and in diabetic microangiopathy. Angiology, 2006, 57: 331-339. [Medline] [CrossRef]

11) Vinciguerra G, Belcaro G, Feragalli B, et al.: PycnoRacer ${ }^{\circledR}$, a fitness drink including Pycnogenol ${ }^{\circledR}$, improves recovery and training in the Cooper test. Panminerva Med, 2019, 61: 457-463. [Medline]

12) Vinciguerra G, Belcaro G, Bonanni E, et al.: Evaluation of the effects of supplementation with Pycnogenol ${ }^{\circledR}$ on fitness in normal subjects with the Army Physical Fitness Test and in performances of athletes in the 100-minute triathlon. J Sports Med Phys Fitness, 2013, 53: 644-654. [Medline]

13) Cormie P, McGuigan MR, Newton RU: Adaptations in athletic performance after ballistic power versus strength training. Med Sci Sports Exerc, 2010, 42: 1582-1598. [Medline] [CrossRef]

14) Weber FS, Silva BG, Cadore LE, et al.: Avaliação isocinética da fadiga em jogadores de futebol profissional. Rev Bras Ciênc Esporte, 2012 , 34: 775-788. [CrossRef]

15) Cavalcante ML, Teixeira PR, Sousa TC, et al.: Index of fatigue quadriceps in soccer athletes after anterior cruciate ligament reconstruction. Rev Bras Ortop, 2016, 51: 535-540. [Medline] [CrossRef]

16) Sangnier S, Tourny-Chollet C: Comparison of the decrease in strength between hamstrings and quadriceps during isokinetic fatigue testing in semiprofessional soccer players. Int J Sports Med, 2007, 28: 952-957. [Medline] [CrossRef]

17) Clarke HH, Shay CT, Mathews DK: Strength decrement index: a new test of muscle fatigue. Arch Phys Med Rehabil, 1955, 36: 376-378. [Medline]

18) Bobbert MF, Hollander AP, Huijing PA: Factors in delayed onset muscular soreness of man. Med Sci Sports Exerc, 1986, 18: 75-81. [Medline] [CrossRef]

19) Sunde A, Støren O, Bjerkaas M, et al.: Maximal strength training improves cycling economy in competitive cyclists. J Strength Cond Res, 2010 , $24: 2157-2165$. [Medline] [CrossRef]

20) Eddens L, Browne S, Stevenson EJ, et al.: The efficacy of protein supplementation during recovery from muscle-damaging concurrent exercise. Appl Physiol Nutr Metab, 2017, 42: 716-724. [Medline] [CrossRef]

21) Décombaz J, Grathwohl D, Pollien P, et al.: Effect of short-duration lipid supplementation on fat oxidation during exercise and cycling performance. Appl Physiol Nutr Metab, 2013, 38: 766-772. [Medline] [CrossRef]

22) Thomson JS, Ali A, Rowlands DS: Leucine-protein supplemented recovery feeding enhances subsequent cycling performance in well-trained men. Appl Physiol Nutr Metab, 2011, 36: 242-253. [Medline] [CrossRef]

23) Ammar A, Bailey SJ, Chtourou H, et al.: Effects of pomegranate supplementation on exercise performance and post-exercise recovery in healthy adults: a systematic review. Br J Nutr, 2018, 120: 1201-1216. [Medline] [CrossRef]

24) Poulsen HE, Loft S, Vistisen K: Extreme exercise and oxidative DNA modification. J Sports Sci, 1996, 14: 343-346. [Medline] [CrossRef]

25) Alessio HM, Hagerman AE, Fulkerson BK, et al.: Generation of reactive oxygen species after exhaustive aerobic and isometric exercise. Med Sci Sports Exerc, 2000, 32: 1576-1581. [Medline] [CrossRef]

26) Bowtell J, Kelly V: Fruit-derived polyphenol supplementation for athlete recovery and performance. Sports Med, 2019, 49: 3-23. [Medline] [CrossRef]

27) Del Coso J, González-Millán C, Salinero JJ, et al.: Muscle damage and its relationship with muscle fatigue during a half-iron triathlon. PLoS One, 2012, 7 : e43280. [Medline] [CrossRef]

28) Margaritis I, Tessier F, Verdera F, et al.: Muscle enzyme release does not predict muscle function impairment after triathlon. J Sports Med Phys Fitness, 1999, 39: 133-139. [Medline]

29) Warren GL, Lowe DA, Armstrong RB: Measurement tools used in the study of eccentric contraction-induced injury. Sports Med, 1999, 27: 43-59. [Medline] [CrossRef] 
30) Gomez-Merino D, Béquet F, Berthelot M, et al.: Evidence that the branched-chain amino acid L-valine prevents exercise-induced release of 5-HT in rat hippocampus. Int J Sports Med, 2001, 22: 317-322. [Medline] [CrossRef]

31) Wiśnik P, Chmura J, Ziemba AW, et al.: The effect of branched chain amino acids on psychomotor performance during treadmill exercise of changing intensity simulating a soccer game. Appl Physiol Nutr Metab, 2011, 36: 856-862. [Medline] [CrossRef]

32) Bescós R, Gonzalez-Haro C, Pujol P, et al.: Effects of dietary L-arginine intake on cardiorespiratory and metabolic adaptation in athletes. Int J Sport Nutr Exerc Metab, 2009, 19: 355-365. [Medline] [CrossRef]

33) Forbes SC, Harber V, Bell GJ: The acute effects of L-arginine on hormonal and metabolic responses during submaximal exercise in trained cyclists. Int J Sport Nutr Exerc Metab, 2013, 23: 369-377. [Medline] [CrossRef]

34) Garrett WE Jr, Califf JC, Bassett FH 3rd: Histochemical correlates of hamstring injuries. Am J Sports Med, 1984, 12: 98-103. [Medline] [CrossRef]

35) Hunter GR, Newcomer BR, Larson-Meyer DE, et al.: Muscle metabolic economy is inversely related to exercise intensity and type II myofiber distribution. Muscle Nerve, 2001, 24: 654-661. [Medline] [CrossRef]

36) Hamada T, Sale DG, MacDougall JD, et al.: Interaction of fibre type, potentiation and fatigue in human knee extensor muscles. Acta Physiol Scand, 2003, 178: 165-173. [Medline] [CrossRef]

37) Li L, Caldwell GE: Muscle coordination in cycling: effect of surface incline and posture. J Appl Physiol 1985, 1998, 85: 927-934. [Medline]

38) Chen SW, Liaw JW, Chan HL, et al.: A real-time fatigue monitoring and analysis system for lower extremity muscles with cycling movement. Sensors (Basel), 2014, 14: 12410-12424. [Medline] [CrossRef]

39) Braakhuis AJ, Hopkins WG: Impact of dietary antioxidants on sport performance: a review. Sports Med, 2015, 45: 939-955. [Medline] [CrossRef] 